\title{
A REVIEW OF ORTHOPAEDIC SURGERY IN BRITAIN
}

\author{
Arthur Rocyn Jones, London, England
}

In the year that Queen Victoria ascended the throne a young physician in England introduced cutting for the correction of deformity. Tenotomy of the Achilles tendon was in itself a simple procedure but it was a new departure in the cure of crippling; its success was sufficient to warrant W. J. Little's embarking upon a close study of the etiology, pathology and rational treatment of deformity. To achieve this purpose hospital accommodation was essential; he found, however, that general hospitals were too preoccupied with a multitude of other ailments to give time or space for the problem of crippling in the community. He therefore aroused the interest of the public to the deplorable state of the crippled poor, and the response was such that in 1840 the Orthopaedic Infirmary was opened in Bloomsbury. In casting about for a name descriptive of the particular function of the institution Little adopted the word orthopaedia ("straight child ") coined by Andry in 1741 from two Greek words. In this way the word orthopaedic was added to our English vocabulary-a term expanded in its meaning by the process of time. It is worth recording that British usage in writing the word has remained faithful to Greek etymology and has refused to pay homage to a confusing phonetic expediency. The work of the Infirmary grew so rapidly that by 1845 it moved to Hanover Square, to a building with greater accommodation, and was granted a Royal Charter of Incorporation wherein its name was changed to the Royal Orthopaedic Hospital.

Orthopaedic surgery in England literally began on the threshold of the Victorian Era. The first decades were occupied in an intense study of the etiology and pathology of deformity as a scientific basis for treatment. Little and his disciple William Adams were particularly active in their investigations, each having a distinctive approach of his own to the problem of crippling. Little, cured by Stromeyer of Hanover of a paralytic equinovarus foot due to poliomyelitis, felt compelled to seek facilities for the treatment of cripples in England. But he remained a physician, although keenly interested in the investigation of deformity and in such correction as was obtainable by splinting, manipulation and tenotomy. His book, entitled $A$ Treatise on Club Foot and the Nature of Analogous Distortions, published in 1839, is a classic. His lectures on deformities of the human frame were collected and published exactly a century ago and his famous paper on infantile spastic paraplegia was an important contribution to neurology and orthopaedics.

The study of deformities was commended to Adams by his great teacher J. H. Green, the philosopher surgeon of St Thomas's Hospital, who encouraged him " to take up the new study of orthopaedy because it opened a wide field for pathological investigation and usefulness." And when elected surgeon to the Royal Orthopaedic Hospital in 1851 Adams was already a well disciplined pathologist of considerable experience. With great energy he explored the whole field of deformity and wrote extensively upon it. What he wrote bears the impress of first-hand knowledge and research. He published a monograph entitled $O n$ the Reparative Process in Human Tendons, based on research on rabbits and observations of tenotomy in human beings over a period of nine years. He spent several years investigating club foot, its causes, pathology and treatment-work which secured for him a Jacksonian Prize. He made an exhaustive study of spinal curvature and published a book upon it; he asserted that "horizontal rotation of the bodies of the vertebrae always precedes lateral curvature." His comfortably fitting spinal support has never been surpassed. Adams made wide use of subcutaneous tenotomy, employing it with great success in the treatment of wryneck and Dupuytren's contracture. 
For many years correction of deformity depended entirely upon stretching, subcutaneous cutting of soft tissues, and splinting, but eventually distorted bone was also attacked. Subcutaneous osteotomy was introduced by Langenbeck in 1852 when he corrected a flexion ankylosis of the hip by blindly cutting the neck of the femur. It is interesting to note that the first surgeon to adventure on osseous correction in England was Stromeyer Little (so named in honour of the surgeon who treated his father), who in 1868 at the London Hospital operated upon a patient aged fourteen years whose both knees had a fixed right-angular flexion, the left due to fibrous ankylosis and the right due to osseous fusion. The left knee was straightened by gradual stretching on an extension apparatus and the right by subcutaneous osteotomy. A carpenter's chisel was inserted through an incision a third of an inch long over the lateral femoral condyle and driven by mallet across the bone. The chisel was several times withdrawn from the femur, but not out of the wound, and each time driven through intact bone until the femur could be broken manually. The hamstrings were severed and the limb was nursed on an extension apparatus. "The result of the treatment related above was satisfactory as the girl could walk easily without assistance."

Although subcutaneous osteotomy had been available for some of the more severe deformities yet its uses were limited. Open operations were forbidden. Hence the whole practice of surgery was very restricted and its progress retarded. There was no lack of dexterity in the art of operating, but post-operative sepsis, pyaemia and hospital gangrene caused such heavy mortality that little beyond emergency surgery was thinkable. Almost up to the last quarter of the nineteenth century there was no security, even for the simplest of operations, against any of these catastrophes. A surgeon having closed his wound was, in the parabolical words of Richard von Volkmann, "like a husbandman who, having sown his field, waits with resignation for what the harvest may bring, and reaps it, fully conscious of his own impotence against the elemental powers, which may pour down on him rain, hurricane and hailstorm." How small was the field of surgery is revealed when it is recalled that in 1865 there were 397 surgical beds at St Bartholomew's Hospital and yet the average annual number of operations during the preceding five years was only 370, of which seventy-eight were amputations.

\section{ANTISEPTIC SURGERY}

In 1867 Joseph Lister announced in the Lancet, and at the Annual Meeting of the British Medical Association in Dublin, his Antiseptic Principle in the practice of surgery. It was the most astonishing and beneficent gift to humanity since the dawn of medicine. It was so revolutionary and contrary to the age-long conception of healing that many of the surgeons of Lister's generation were unconvinced of its value or frankly repudiated it. But Lister continued steadfastly experimenting in his laboratory for the improvement of the application of the antiseptic system, at the same time endeavouring to persuade the profession to adopt it; the main reason for his leaving Edinburgh for King's College Hospital was the opportunity afforded of demonstrating the great virtue of antiseptic surgery to the London schools. The younger surgeons, free from prejudice, became converted and it was they who really embraced the new system and started the phenomenal advance in surgery. In the forefront was Lister's dresser, William Macewen of Glasgow. He perfected linear osteotomy by antiseptic surgery and devised for the purpose a special bone-cutting instrument, bevelled on both sides, which he called an osteotome. In 1879 he succeeded in promoting the reconstruction of a humerus, most of which was destroyed by osteomyelitis, by sewing along the bed of the absent shaft bone chips removed from other patients for the correction of deformity. This was the first time that bone had been successfully transplanted from one human to another-an achievement of fundamental importance for orthopaedic surgery and one which stirred the imagination of T. H. Huxley when Macewen communicated a paper to the Royal Society upon this work. Furthermore it started Macewen on thirty years of clinical and experimental investigation on The Growth of Bone, culminating in 1912 in his great book of that title. Another pupil of Lister, 
Thomas Annandale of Edinburgh, explored the knee joint for internal derangement and, finding a torn cartilage, sewed it back in position which resulted in comfortable restoration of function of the joint. For a surgeon to have been able to explore the knee joint without any inflammatory reaction or any delay in union of his wound was a good test of the efficacy of antiseptic surgery. During the years immediately following Herbert Allingham of St George's Hospital evolved a complete technique for exploration of the knee joint with removal of loose cartilage when present.

The dozen years from 1870 onwards were a peculiarly flowering period in orthopaedic surgery, for apart from the initial impact of antisepsis and its effect on bone and joint surgery there were other contributions of importance. Sir James Paget gave an exhaustive and complete description of a deforming inflammatory disease of bone which he called osteitis deformans, and he drew attention to the occurrence of a non-inflammatory avascular necrosis of bone as the result of trauma. In 1875 Hugh Owen Thomas published his classical monograph on Diseases of the Hip, Knee and Ankle Joints. It at once revealed him as an original thinker in surgery. The burden of his teaching was rest for diseased joints, conveyed in his often repeated formula "enforced, uninterrupted and prolonged rest." For Owen Thomas rest had a precise meaning. It could only be obtained by striving for immobility. This he endeavoured to achieve by his ingenious but simple splints. In the period that he wrote he undoubtedly secured by rest and fresh air such healing of tuberculous joints that hardly occurred outside his own practice. His famous caliper, originally designed for joint disease, was subsequently used for fractures of the lower limb. Nothing is more symbolic of the genius of Owen Thomas than this splint, surprisingly simple in construction but peculiarly adaptable in its uses. It is a basic equipment wherever fractures are treated. The modern use of the caliper is frequently combined with traction by weight and pulley, an indispensable aid to skeletal surgery introduced for the first time by John Haddy James of Exeter and described by him, with illustrations of its use, in an address on surgery delivered at Liverpool in 1839.

Pasteur with his revolutionary germ theory of disease had prepared the way for the introduction of Lister's antiseptic system. And Koch, stimulated to seek what maladies were of microbic origin, found in 1882 that a bacillus was the cause of scrofula and phthisis, thereby proving their unity. The importance of that discovery was beyond compute in its significance for human well-being. It provided a scientific basis for all the various forms of treatment that followed and for the study of the domestic and social environment of those affected by tuberculosis. And although the tubercle bacillus has proved peculiarly resistant to attack its immunity shows some sign of weakening when confronted by some of the later antibiotics. At long last this protean disease is clearly on the decline in Britain.

\section{OPEN OPERATIONS ON BONE}

When orthopaedic surgeons had grasped the practical details of antiseptic surgery it was natural that they should begin cautiously with its application in osteotomy, where a small skin incision was adequate. It was not until the 'nineties that bolder surgery began. Robert Jones started performing arthrodesis of the ankle and knee for severe infantile paralysis, and by 1894 he was able to report fifteen patients upon whom this operation, introduced by Albert of Vienna in 1875, had been carried out. He spoke more favourably of this operation for the ankle than for the knee. In 1908 he described his well known two-stage arthrodesis operation for paralytic talipes calcaneo-cavus. Again Muirhead Little advocated cuneiform tarsectomy for resistant talipes in adults and adolescents, after a successful removal of a wedge from the neck of the talus and calcaneum. But a leading orthopaedic surgeon, with some alarm lest others should follow Little, felt obliged to issue a warning that "only those who are perfectly sure of their antiseptic methods should undertake tarsectomy."

The other procedure to arouse attention was tendon transplantation for infantile paralysis, introduced by Nicoladoni in 1881 when he attached the peroneus longus and brevis tendons

VOL. 38 B, NO. 1, FEBRUARY 1956 
to the tendo calcaneus for paralytic calcaneo-valgus. The patient, when shown six months later at the Salzburg Surgical Congress, exhibited well restored plantar flexion of the foot. But it was not until 1897 that tendon transplantation was first performed in England, when Frederick Eve at the London Hospital operated upon four patients with paralytic feet, one with talipes equinovarus in whom the tibialis posterior was attached to the extensor digitorum longus and a strip of the tendo calcaneus was attached to the peroneus longus; in two months the child walked well. The following year T. H. Openshaw wrote an excellent paper on tendon transplantation, full of detail indicating the selection of tendons for transplanting, rules for successful grafting, the cause of failure, and the best suture material with comment on its preparation. In 1903 appeared the classic monograph Surgery of Paralysis by Tubby and Robert Jones. The application of the new surgery to the whole field of flaccid and spastic paralysis was well covered. Tendon transplantation and arthrodesis were considered separately and in combination. About the most successful of all transplantations is that for radial nerve paralysis evolved by Robert Jones during the first world war. Congenital and paralytic deformities claimed most of the interest of orthopaedic surgeons; the potential crippling of trauma had not yet attracted their particular attention. Fractures were usually treated in the casualty departments of hospitals; patients with severe injuries were admitted as in-patients. But the standard of treatment, judged by the average functional result of a limb fracture, lagged behind that obtaining in other branches of surgery. For many years a fractured femur, whether of neck or shaft, was treated by tying a long Liston splint to the body and lower limb with possibly strapping extension. Fibrous union of a fractured femoral neck, with its attendant instability, was an inevitable expectation. There were a few surgeons, however, who were disturbed by this inadequacy of surgery and who regarded it as their duty to restore to an individual the full use of a limb broken by accident. Prominent among them were Hugh Owen Thomas and Robert Jones, to whom flowed the casualties of Merseyside and those incident to the cutting of the Manchester Ship Canal. Stress was laid on the accurate re-apposition of broken ends of bones, and on the restoration of true alignment, by powerful traction and skilled manipulation under anaesthesia. The limb was subsequently immobilised in a caliper or in an arm splint modelled on the caliper, with accessory malleable gutter splints or collar-and-cuff.

After the experience of a decade in the handling of fractures Arbuthnot Lane had reached the conclusion that for the intractable fracture open reduction with rigid fixation was necessary. Speaking of simple oblique fractures of the tibia and fibula in certain classes of labouring men he stated: "I have no hesitation whatever in asserting that, under the methods of treatment at present adopted, not only is the man totally incapacitated from earning a living for an unnecessarily long period but in a considerable proportion of cases he is unable subsequently to perform such heavy work as he was able to do before the injury, so that he is obliged to follow some less remunerative pursuit if indeed he has not to depend solely on charity." On January 8, 1894, Lane operated upon a man with oblique fractures of tibia and fibula after failing to reduce them by manipulation under anaesthesia and subsequent splinting for a few weeks with no sign of healing. "The fracture in the tibia was exposed by an incision $4 \frac{1}{2}$ inches long when its direction was seen to be very oblique running downwards, outwards and backwards. Several small fragments of bone and muscle intervened between the ends of the bones... After much difficulty the broken surfaces were brought into accurate apposition by means of lion forceps and two screws were inserted." Thereafter he persisted with the operative treatment of fractures. In an ununited fracture of the neck of the femur he obtained osseous union by passing two screws from the greater trochanter through the neck into the femoral head, thereby anticipating the later nailing operation. It was sometime after 1905 that he introduced his well known steel plates and screws; with these he extended the range of fracture operations.

Lister in 1877 , with antiseptic precautions, wired a fractured patella, obtaining osseous 
union, a result rarely obtained by external splinting; but despite the success of the operation he was subjected to some unfavourable criticism for this "unjustifiable procedure." And Lane by his operating on simple fractures raised a storm of criticism and even abuse. He soon realised that if the operative treatment of fractures was to be safe rigorous asepsis was essential; he therefore evolved an unremitting no-touch technique which of itself has had a transforming effect on operative orthopaedic surgery.

There is one of the lesser disabilities, which is very common and often very painful, that is deserving of notice-namely hallux valgus. For this there was no radical cure until 1885 . In that year J. N. C. Davies Colley of Guy's Hospital performed his operation of removing the proximal part of the first phalanx, whereby the great toe was straightened, the patient relieved of symptoms, and the treading power of the head of the first metatarsal preserved. Various modifications have been adopted since, including the removal of the head of the metatarsal, but for the severe type of the deformity Davies Colley's operation, with the removal of the prominent inner part of the metatarsal head, has stood the test of seventy years.

Many of the advances in medicine have been dependent upon discoveries of pure scientific origin. In 1800 Sir Humphry Davy produced complete experimental evidence of the power of nitrous oxide to induce safe anaesthesia. Pasteur, another chemist, proved the microbic origin of disease in plants and animals; and in December 1895 W. K. Röntgen, a physicist of Würzburg, announced the discovery of $x$-rays which, among their many uses, have enabled surgeons to obtain a knowledge of the pathology of living bone and joint afflicted by disease or injury and to gain precision in some orthopaedic procedures. A voluntary worker in Liverpool, on receiving the Frankfürter Zeitung containing an article on Röntgen's discovery, translated the narrative for Robert Jones, who at once crossed to the continent and brought back an x-ray apparatus by means of which he and Thurstan Holland took a picture of a boy's injured wrist. It displayed a small embedded bullet; the two marvelling at the revelation.

The advances in orthopaedic surgery led to a greater interchange of ideas among younger surgeons. At the annual meeting of the British Medical Association in Bristol in 1894 an informal meeting was held with the object of founding an orthopaedic society, and on November 3 of the same year the British Orthopaedic Society was formed, the avowed object of which was the advancement of orthopaedic surgery. Forty members were enrolled. Three meetings a year were held. The first took place on January 31, 1895, at the Royal MedicoChirurgical Society's rooms. Subsequent meetings were held at Liverpool, Birmingham and Bath, among other places. But in spite of its stimulating discussions the Society only lasted a few years; four slender volumes of its transactions were published. It had served a useful purpose because it had brought together men who were interested in orthopaedic surgery, and the memory of this coordinated effort lingered. They had first met together at the rooms of the Royal Medico-Chirurgical Society and they were destined to meet again fourteen years later in the new house of the same Society, renamed the Royal Society of Medicine, to form an Orthopaedic Sub-section of the Section of Surgery.

\section{EMERGENCE OF ORTHOPAEDIC SURGERY AS A DISTINCT SPECIALITY}

At the beginning of the twentieth century it was assumed that a surgeon who had completed the customary apprenticeship was able to deal adequately with almost any surgical condition for which there was a known remedy. This attitude was encouraged by the romantic experience of the 'nineties during which the full impact of anaesthesia and antisepsis on surgery was felt; it was a decade of adventure. Most teaching hospitals felt that there was no need for special departments, although two or three of them delegated a surgeon, as a part-time appointment, to the duty of taking charge of ophthalmic or orthopaedic patients. But Jonathan Hutchinson, with clear foresight, declared that selective specialisation would become inevitable; the expanding knowledge of surgery, with its multiform technique, would be beyond the power of one man to encompass. The first indication of the advancing status of orthopaedic surgery,

vol. $38 \mathrm{~B}$, NO. 1, FEBruary 1956 
in a hospital service, occurred at Charing Cross Hospital in 1906 when Mr H. A. T. Fairbank was appointed orthopaedic surgeon in succession to F. C. Wallis, who had been promoted surgeon. Sir Frederick Wallis had been appointed assistant surgeon in 1893 and in the following year was also given charge of an orthopaedic department. His main interest, however, was in rectal surgery, in which he achieved great distinction and was the author of a manual on that subject. When he became full surgeon he resigned his post as orthopaedic surgeon. Mr Fairbank was surgical registrar, and the Board of Governors were anxious to retain his services permanently for the hospital, but there was no vacancy on the ordinary surgical staff; they thereupon appointed him, on March 14, 1906, to the vacant post of orthopaedic surgeon. He differed from his predecessor in that he had no surgical duties outside his own department of orthopaedic surgery. It was an unparalleled appointment. Six years later similar appointments were made at St Bartholomew's and at Guy's Hospitals.

At that time there were scarcely a dozen surgeons in England who maintained a constant interest in skeletal disabilities, but the following half-century has seen a remarkable change. During this period Sir Thomas Fairbank has been a leading influence in moulding the shape of orthopaedic surgery in Britain; indeed he has come to hold a unique place in the heart and mind of all those who follow the same calling. His vitality and sustained interest in orthopaedic surgery are a delight to many. He has played an honoured part in the service of his country, in hospital organisation and as an advisory servant of the State. But his most personal and abiding influence has been imparted to his writings; in these he has always striven to base advancing knowledge on scientific fact derived from pathology. He has devoted most attention to skeletal disabilities such as congenital dislocation of the hip, coxa vara, and in particular diseases of bone which culminated in his greatest work, An Atlas of General Affections of the Skeleton, published in 1951.

His description of the anatomy of congenital dislocation of the hip is about the best on this subject that has appeared. He drew attention to the changes in the bone behind the acetabulum, with the occasional formation of a facet at this spot, to the arrangement of the capsule, and to the importance of the ischio-capsular band which forms a sling over the neck of the femur. The work is illustrated by many beautiful drawings of specimens examined by Sir Thomas in the Musée Dupuytren in Paris. The original drawings are now available among the archives of the British Orthopaedic Association. His long experience covers the whole period of treatment by manipulation in this country, for he was present at the demonstration by Lorenz at the City Orthopaedic Hospital in 1903. He has said that if the dislocation is reduced before the age of three years, or better still before the age of two, a permanent cure ensues in a very large percentage of patients. The hip will be approximately normal and stand the wear and tear of life almost, though not quite, as well as a hip that has never been abnormal. During the progress of treatment he laid great stress on one guiding sign, namely "The position of the femoral head with regard to the centre of the acetabulum is of greater prognostic value than the shape of the upper margin of the socket." Furthermore, even with the help of open reduction the age of six years for a bilateral dislocation and nine for a unilateral should not be exceeded. For the shelf operation the ideal patient was one of four or five years with a unilateral dislocation and unusually poor acetabular margins.

In his study of coxa vara he succeeded, by a process of close reasoning and the examination of many radiographs, in separating a particular variety of the congenital form of this malady to which the name of infantile or cervical coxa vara had been given. He pointed out the recurring characteristic triangular fragment of bone occupying the lower part of the femoral neck close to the head and which later became fused to neck and shaft. This pathological phenomenon he attributed to developmental error, a supposition that was supported by its presence in children with other irregularities of bone growth.

The "Atlas" is the rich harvest gleaned during a lifetime of patient observation, careful clinical recording and the collecting of innumerable radiographs. In this book the author 
has gathered together from scientific journals his many contributions on those affections of the skeleton where more than one bone is involved. The introductory essay on these osseous maladies is a most valuable feature of the work, clarifying by intimate knowledge many vague notions about their pathology. A classification is drawn up based on their etiology, and tables are given which are helpful in diagnosis, particularly the one on blood chemistry. The Atlas is of supreme worth as a work of reference in a field of surgery in which uncertainty is apt to reign. It has a value beyond that of a period; it is one of the best scientific contributions that have emerged in British orthopaedic surgery.

In the years immediately preceding the first world war there were clear signs of an increasing interest and activity in orthopaedic surgery. In 1912 Macewen's classic The Growth of Bone and Tubby's great two-volume text-book appeared; in the same year St Bartholomew's and Guy's Hospitals formed orthopaedic departments independent of general surgery, with R. C. Elmslie and W. H. Trethowan respectively in charge. Elmslie was about the last to hold a resident appointment at the old Royal Orthopaedic Hospital in Hanover Square. He returned to St Bartholomew's to become chief assistant in an orthopaedic department which had been started in 1867, with an assistant surgeon usually in charge. He also spent five years in the pathology department gaining an experience that influenced his subsequent approach to all orthopaedic problems.

His work on the pathology of coxa vara, communicated in his Erasmus Wilson lecture of 1907 and in a subsequent monograph, is outstanding in its scientific presentation; it is the original source of much of our knowledge of this disability. He classified coxa vara into three main groups, those due to 1) injury, 2) bone softening from disease, and 3) idiopathic, which he subdivided into congenital, infantile or cervical, adolescent. All these varieties had already been recognised, but the infantile or cervical group was so named by Elmslie himself; in it he described the V-shaped gap in the upper part of the neck but was inclined to believe that this type of coxa vara was due to injury. Several years later Fairbank with good reason regarded it as of congenital origin. In describing adolescent coxa vara Elmslie marshalled convincing evidence to prove that it was due to trauma, stating that "instead of the original opinion that accidents to the femoral neck in children were rare and were due to severe injury, we must accept it as demonstrated that such accidents are common, that a very slight injury may be sufficient to produce them, and the immediate disability may be correspondingly slight ... I have recorded a case of a boy in whom this accident occurred during a hurdle race, which he was able to finish and win, and cases in which the epiphysis is apparently separated by very slight wrenches of the hip joint, the deformity only showing itself some months afterwards, are comparatively common. The actual site of the injury in the neck of the femur has been a matter of some dispute. I have no doubt that during adolescence the injury is situated close up to the epiphyseal line of the head, but not of course actually through the epiphyseal cartilage, so that, technically speaking, the injury should be classed as a separation of the epiphysis."

Elmslie also made a special study of fibrocystic disease of bones, upon which he wrote a great deal. He communicated an extensive paper to the British Journal of Surgery in 1914. He examined a large number of specimens in many of the pathological museums of London, giving their clinical history and histological sections. He concluded that in calling the malady a fibrocystic disease did not imply a knowledge of its total pathology, for it was uncertain whether it was one disease or several, and whether it was an inflammatory process, new growth, or simply an instance of disordered bone growth. He wrote: "It would rather appear that there is a general disturbance in the processes of growth or alteration in the bone. That in the course of this there is 1 ) a fibrous metaplasia of the marrow; 2) an excessive formation and activity of the giant cells; 3 ) an active absorption of bone, with coincident formation of new bone and cartilage. That in places the fibrous mataplasia may be most evident, leading to the formation of fibrous masses; in other places cysts may be produced, either by the action 
of the giant cells or by the degeneration in the fibrous tissue; and that in still other places there may be abundant formation of bone-which may or may not be properly calcified-and of cartilage or fibro-cartilage; whilst, last of all, the giant cells may be produced in such numbers as to form a veritable myeloma. These changes appear to have a period of activity, and then to become stationary."

We owe to Elmslie an extension of our knowledge of the pathology of bone disease, a subject by which he was ever fascinated. His orderly judicious mind enabled him speedily to select what was relevant to the solution of any problem that confronted him. In an open discussion he would express his considered opinion in a clear unfaltering style in a voice of considerable charm; all the more remarkable because, in spite of appearance, he was never really in full health. He exercised a profound influence on his younger colleagues, always inculcating upon them the fundamental importance of pathology in relation to orthopaedic surgery, a subject to which he turned again in his presidential address to the British Orthopaedic Association.

\section{ORTHOPAEDIC TEACHING}

The greater recognition of orthopaedic surgery by teaching hospitals secured its regular tuition to undergraduates. But before this period sound teaching in this branch of surgery had been available in several text-books, the best of which was published by $\mathrm{A}$. $\mathrm{H}$. Tubby in 1896. This work was an authoritative presentation of orthopaedic surgery as understood in the closing years of the nineteenth century; the author cast his net widely in order to gather the theory and practice of surgeons in America and the Continent. His own researches on tendon repair were described at length. In 1912 a new edition appeared with the ominous title Deformities including Diseases of the Bones and Joints. Owing to the advance of orthopaedic surgery between the two editions, and the author's deliberate inclusion of skeletal diseases within its range, the whole work was rewritten with the various subjects arranged according to their etiology and pathology rather than on a regional classification. It was issued in two large volumes; it contained seventy plates and more than a thousand illustrations, of which four hundred were original. In the following words Tubby boldly declared that " Orthopaedic surgery is the surgery of the entire locomotor apparatus. In England, contrary to the custom abroad, works written on 'Orthopaedic Surgery,' although they have dealt with tuberculosis of the spine, have not included tuberculous and many other forms of diseases of the bones and joints elsewhere. And this, in spite of the obvious fact that in the practice of Orthopaedic Surgery a surgeon is constantly called upon to deal with such morbid conditions and their results. It has been my attempt to remedy this somewhat illogical state of affairs, and to treat the subject from its actual standpoint, which is the surgery of the entire locomotor apparatus, dealing not only with actual deformities, but also with those morbid processes which involve potential deformity. It is not claimed that the scope of the orthopaedic surgeon's work is thereby enlarged, since he undertakes already the treatment of malformations and deformities of the muscular and osseous systems, which demands a full acquaintance with the pathology of such conditions and with the essential therapeutic methods. A considerable portion of the work has therefore been devoted to a description of arthritic and osseous diseases." This was the best text-book on orthopaedic surgery in any language and has scarcely been equalled since; the clear descriptive power of the author was not the least of its features. It raised the prestige of British orthopaedic surgery.

Tubby devoted a good deal of attention to tendon transplantation, to which he was first attracted by the work of Lange and Vulpius during his studies at Halle and Leipzig. He devised an operation by which the pronator radii teres was converted into a supinator; sometimes he combined this procedure with transference of the flexor carpi ulnaris to the extensor carpi ulnaris and of the radial flexor to the radial extensors. The Surgery of Paralysis (1903) by Tubby and Robert Jones was on a theme in which both were intensely interested; each had 
made a pioneering contribution on tendon transference. Furthermore each was eager for the advancement of orthopaedic surgery and this book was a sign of their happy cooperation.

The developing interest in this branch of surgery was further stimulated by the holding of the Seventeenth International Congress of Medicine in London in August 1913. Never before in the history of orthopaedic surgery in Britain did so many leading orthopaedic surgeons from Europe and America assemble together as they did to the Section of Orthopaedics over which Robert Jones presided. The papers and discussions were fully representative of the whole range of orthopaedic surgery. Among those who took part in discussion were Lucas-Championnière, Ridlon, Whitman, Lovett, Brackett, Baer, Putti, Spitzy, Vulpius, Dollinger and Rollier. A paper that attracted considerable attention was that by Fred H. Albee on "Original uses of the Bone Graft as a treatment for Ununited Fracture, Certain Deformities, and Pott's Disease." At the Royal National Orthopaedic Hospital the technique of bone grafting was demonstrated by Albee before a crowded audience. With his motor-driven twin saw an autogenous graft was cut from a tibia and implanted in the split spinous processes of the vertebrae of a patient with Pott's disease. The pervading cordiality that prevailed at the president's dinner to the members of the section evoked no whisper of the deep cleavage that would occur in twelve months.

\section{THE FIRST WORLD WAR}

In August 1914 the thunder of a world war crashed, suddenly causing a deluge of casualties. The Army Medical Service made hurried improvisation to meet this bewildering situation. Leading physicians and surgeons were appointed to various commands. Tubby went out with the British Mediterranean Force and was stationed at Alexandria with Sir Victor Horsley. He gave a graphic account of the Gallipoli Campaign and of the sufferings of the troops. He organised fracture and orthopaedic treatment in Egypt but was unable to get sanction for segregation of fracture patients or for special hospitals for their treatment. In Britain Robert Jones was attached to the Western Command and in his tour of its hospitals he found that " no provision of any sort was made for cases crippled and deformed, and early evacuation was both instruction and the routine. The result was that many men were discharged from the Army in a very large number of cases totally unfitted either for military or civilian life." To stop this state of things he succeeded in persuading the War Office in 1915 to reserve 400 beds at the Military Hospital at Alder Hey, to which wounded soldiers requiring orthopaedic treatment might be transferred from other hospitals. The same year he went to France and gave demonstrations at the casualty clearing stations in the use of the Thomas splints; these splints became a permanent part of war equipment. The caliper in particular saved thousands of limbs and helped in the comfortable transport of the wounded. He also wrote two small manuals which had a widespread influence on all fronts, the one Injuries of Joints and the other Notes on Military Orthopaedics.

In 1916 the newly built Hammersmith Infirmary at Shepherd's Bush was converted into a military orthopaedic hospital similar to that at Alder Hey, and was staffed by younger orthopaedic surgeons, some of whom had been trained at Liverpool. Military orthopaedic hospitals were established later in other parts of the country; these were staffed by surgeons drafted from Shepherd's Bush and by relays of surgeons from America in charge of Goldthwait. This chain of hospitals provided fracture and orthopaedic treatment, with rehabilitation for the wounded soldier in reasonable proximity to his own home. This was a great achievement and was only accomplished after much obstruction; it was a great triumph for the persuasive persistence and energy of Sir Robert Jones.

The establishing of military orthopaedic hospitals with the appointment of Sir Robert Jones as Inspector of Military Orthopaedics was a clear indication of the capacity of orthopaedic surgery to prevent crippling from skeletal injuries and of its ability to help in restoration of manpower for battlefield or factory. And when later the military orthopaedic surgeon took 
off his uniform on his return to civilian life he did not divest himself of his skill but was able to apply it to the accidents of industry. With the restoration of peace the special military hospitals began to disappear, but soon there arose others in another form like those at Oxford, Stanmore, Harlow Wood and Exeter-country hospitals following the pattern of the pioneer hospital of Robert Jones and Agnes Hunt at Baschurch and Oswestry with its network of clinics in adjacent counties. All these hospitals attracted younger surgeons in whom the war had cultivated a taste for orthopaedic surgery and who were anxious to gain experience in the care of civilians with skeletal disorders.

The military orthopaedic hospitals had diffused greater knowledge of the practice of orthopaedic surgery than at any other time, and the response of the younger generation was reflected in the crowding of scientific meetings for its discussion. It was this inspiring atmosphere that encouraged Robert Jones, with the help of Robert Osgood of Boston, to form a British society on the model of the American Orthopaedic Association. The inaugural meeting of the new British Orthopaedic Association was held at Roehampton House on February 2, 1918, with Muirhead Little as president. Little was a man of rare culture, beloved by patients and colleagues, with an encyclopaedic knowledge of orthopaedic literature. He took a leading part in establishing Queen Mary's Hospital at Roehampton as an artificial limb-fitting centre, and he wrote a monograph on Artificial Limbs and Amputation Stumps, and an admirable history of the British Medical Association for its centenary meeting in London in 1932. His wife started a hospital school at the National Orthopaedic Hospital as early as 1892 , and its success was such that the local education authority became responsible for it. It was not until the Fisher Education Act of 1918 that education and treatment of physically defective children of school age became compulsory. About twenty founding members of the new Association were enrolled, forming a group most of whom had worked with Robert Jones. Under his leadership they enlarged the boundaries of orthopaedic surgery in Britain.

\section{BETWEEN THE WARS}

During the post-war decades there was remarkable progress in orthopaedic surgery. Through the military orthopaedic hospitals which he had organised Robert Jones gave convincing proof of the value of segregation, continuity of treatment and unity of control in the successful treatment of skeletal injuries-three principles he had learnt long ago when responsible for the treatment of casualties incident to the cutting of the Manchester Ship Canal. Furthermore the particular experience of the men chosen for the staffing of these hospitals implied that the care of fractures and allied injuries was a part of orthopaedic surgery, which is the surgery of the entire locomotor system. The first ostensible linking of fractures with an orthopaedic department of a hospital was made by Sir Harry Platt when he established a fracture clinic at Ancoats Hospital, Manchester. This was followed with a similar clinic by Sir Reginald Watson-Jones at Liverpool Royal Infirmary.

No-one contributed more to our knowledge of the operative treatment of fractures than Hey Groves. He conducted numerous experimental observations on bone grafting in animals, the results of which he embodied in his Jacksonian Prize Essay of 1916. He employed every form of bone graft and adopted many forms of fixation. He concluded that the "most ideal graft is a piece of living bone used in its entire thickness... The success of a living graft depends very largely upon: $a$ ) the extent of its contact with living bone; $b$ ) the accuracy of its apposition; $c$ ) the firmness of its fixation." He also made extensive researches upon internal splinting in animals, using plates and intramedullary pegs of bone and metal. He applied all this experimental work on bone grafting and metal splinting in the treatment of human fractures. The combined work was ultimately published in his book, On Modern Methods of Treating Fractures, an enlarged second edition of which was published in 1921. During the period of these researches the non-electrolytic metals had not yet been introduced, but it is interesting to note that he proved the effectiveness of the intramedullary steel peg in 
fractures of long bones. Again commenting on the frequent difficulty of controlling the upper short fragment in transverse subtrochanteric fractures of the femur, he bound the fragments together in alignment by an intramedullary bone peg six inches long introduced at the top of the greater trochanter. By this procedure he anticipated intramedullary nailing. Hey Groves was largely responsible for the foundation of the British Journal of Surgery. Its high standard from its inception owes much to his tireless devotion as first editor for nearly thirty years; by this work " he built for himself his best monument."

Among the many problems of skeletal trauma those involving the shoulder have commanded a good deal of study varying from the stiffness of traumatic periarthritis and injury of the rotator cuff to that of frank dislocation. The treatment of recurring dislocation left much to be desired owing to uncertainty of cure by the operative procedures adopted. This was due mainly to operations performed without reference to pathology, although Curling of the London Hospital had long since discovered a capsular detachment and humeral defect in such dislocations; but his disclosure was forgotten. Blundell Bankart in 1923 rightly stressed the importance of basing treatment on pathology and pointed out the detachment of the glenoid labrum, advocating its reattachment and repair in all patients, supporting his contention by an impressive high proportion of permanent cures. Putti and Platt independently devised an effective and less difficult operation; subscapularis was detached an inch from its insertion and the distal portion attached to periosteum and soft tissues in front of the neck of the scapula with the arm rotated inwards; the proximal portion was sutured to tissue at the lesser tuberosity of humerus. This procedure checked lateral rotation of the humerus, which was the movement producing dislocation. Bankart's operation has stood the test of over twenty years and is the best known of his contributions. He exerted great influence in the development of orthopaedic surgery in Britain. As surgical registrar at Guy's Hospital he assisted Arbuthnot Lane, learning from that master surgeon a rapid dexterity and a faultless no-touch technique. He was a quick operator, who neglected nothing, and was a most accomplished surgeon, for he combined neurosurgery and children's surgery with that of orthopaedic surgery. For several years he performed all the neurosurgery at Maida Vale Hospital for Nervous Diseases. He was about the first to perform Stoffel's operation for spastic paralysis, enabling very many children to walk and attend special schools, and one of the first in this country to perform autogenous bone grafting. He planned and rehearsed an attack on difficult territory with meticulous care; he cured by radical excision patients exhausted from chronic intractable sinus-riddled tuberculous hips. He was so absorbed in the art of operative orthopaedic surgery that he inspired his pupils to aim at excellence in its technique.

The modern teaching of skeletal injuries was gathered up in a comprehensive text-book by Sir Reginald Watson-Jones entitled Fractures and other Bone and Joint Injuries published in 1940. It was the best work on the subject that ever appeared and it was not without significance that it was written by an orthopaedic surgeon.

Although the war had focused attention on traumatic disabilities yet other orthopaedic problems soon attracted interest, amongst which were disorders of the foot. Paralytic instability occupied a prominent place. In 1922 Naughton Dunn introduced triple arthrodesis, including excision of the navicular bone, for calcaneo-cavus and other deformities, combining it when necessary with tendon transplantation. Dunn became lecturer in orthopaedic surgery at Birmingham University after a training at Liverpool and a period as surgeon at Shepherd's Bush. For paralytic calcaneo-cavus Elmslie performed a two-stage operation, the first stage corrected the cavus deformity by soft-tissue stripping and talo-navicular arthrodesis, the second corrected calcaneus by arthrodesis of the posterior part of subtalar joint, fixing a strip of the tendo calcaneus to the tibia and attaching the peronei, flexor digitorum longus and tibialis posterior to the back of the calcaneum. In 1927 Lambrinudi published his ingenious operation for drop foot, a procedure he evolved while directing a small clinic at

VOL. $38 \mathrm{~B}$, NO. 1 , FEBRUARY 1956 
Balaam Street, East London, before his staff appointment to Guy's Hospital. The anteroinferior part of head of the talus was removed as well as the postero-inferior quarter of the navicular. The remaining part of the head of the talus was then insinuated into the gap in the navicular; the subtalar joint alone was arthrodesed. Lambrinudi had a penetrating intellect and expressed hinself in an original and stimulating fashion on many orthopaedic problems. He held that there were " no principles of orthopaedics as opposed to principles of medicine. There were only principles of medicine, which in orthopaedics should be applied to the restoration and maintenance of the function of locomotion, using the term in its widest sense. Always he laid stress on function as the only true guide in treatment and not only function of the body as a whole but also its proper functioning in relation to its social environment."

A foot deformity of recurring interest is congenital club foot, for which manipulation and splinting have been the basic means of correction. Denis Browne produced effective splints of simple design although they lacked the anatomical precision of the older and more expensive appliances of Scarpa and Adams. For the stubborn or neglected deformity, which could not be completely corrected by manipulation, open section of resisting or shortened ligaments, the so-called soft-tissue operation, was adopted by Elmslie and Trethowan and also by Brockman, who reinvestigated the pathology of club foot, emphasising that it was of the nature of a subluxation inwards of the navicular bone and interior part of the foot around a fixed muscle-free talus. Trethowan, because of his abhorrence of the wrench as an instrument of correction, was all the more disposed to lay bare the tarsal ligaments and cut or excise what he saw offending. Trethowan, an ardent disciple of Arbuthnot Lane, confessing that he himself was not naturally dexterous, by sheer disciplinary practice became the outstanding orthopaedic craftsman of his time. To see him bone grafting or openly correcting and fixing a difficult fracture of the ankle was an exhilarating experience. Like his master he was notorious for the length of his incisions but remarkable for the dryness of his wounds; he would say: " if you get down to the bone at its most superficial part and stay there you cannot cut anything of importance."

Until the beginning of the century congenital dislocation of the hip was considered incurable, but interest revived in this deformity after the demonstration of the Paci-Lorenz manipulation at the City Orthopaedic Hospital in 1903. Jackson Clarke took a leading part in fostering manipulative reduction and retention by plaster. He was highly successful in his late results and published a monograph upon the subject. After the war attention was directed to the dislocation that resisted manual reduction or in which the femoral head was unstable after reposition. For this type of hip Sir Thomas Fairbank and Sir Harry Platt advocated exploration to remove capsular obstruction with or without the prising down of an oblique ill-formed acetabular roof. In 1927 Putti, with his exceptional experience of this almost racial malady, successfully campaigned to get infant patients under the age of one year to the Rizzoli Institute where he was able to reduce a dislocation by gradual abduction on a divaricator. The success of this procedure influenced the surgeons at the Wingfield-Morris Orthopaedic Hospital to extend continuous traction to older infants, using an adjustable abduction frame for the purpose.

Reduction by gradual traction or manipulation, with retention by plaster or special splint, is still the method of choice in Britain. This procedure is justified by the high proportion of permanent cures achieved by surgeons in the earlier days of manipulation. Laming Evans in particular obtained results that were unsurpassed chiefly because of his skill as a manipulator and his meticulous after-care. A child with a unilateral dislocation was permitted early walking in a plaster with a high patten on the shoe of the affected side. When the plaster was discarded a $1 \frac{1}{2}$-inch patten was worn on the shoe of the sound side to promote abduction of the opposite limb; up to two years the child slept in a removable plaster with the thigh abducted 90 degrees with some flexion. Again he would by patient repeated manipulation produce an astonishingly 
good correction of a badly deformed club foot where a less disciplined junior would seek relief by open section. Evans had a sensitive easily provoked personality and was deeply conscious of his duty to his patients, who loved and feared him alternately but who continued to crowd his clinic. For the advancement of orthopaedic surgery he bequeathed $£ 20,743$, the ultimate residue of his estate, to the Royal College of Surgeons, whose Council from the income has instituted a research scholarship known as the Laming Evans Fellowship.

The first surgeon in Britain to study and treat tuberculosis of all joints on any considerable scale was Hugh Owen Thomas. Before he announced his famous hip and knee splints for joint disease he had tried his methods and checked his results on more than a thousand patients. He was fully alive to the value of rest, good feeding, fresh air and sunshine in the cure of joint tuberculosis. Even in dwellings of the very poor he insisted on nursing children out of doors on beds improvised for the purpose. Robert Jones continued the conservative tradition of Thomas when excision, flushing and curetting were common practice.

One of the earliest hospitals for children suffering from surgical tuberculosis was opened at Alton in 1908 and named after its founder the Lord Mayor Treloar Cripples' Hospital. Sir Henry Gauvain was appointed superintendent, and under his guidance the hospital achieved a national reputation. He arrived at Alton to find an advisory medical board still reluctant to give up radical operations, but Gauvain went to Berck-sur-Mer to study conservative open-air treatment and the technique of making and using plaster splints. He collaborated with Calvé in advocating aspiration instead of free incision for evacuation of tuberculous abscesses. He was convinced of the value of sunbathing, and was a pioneer in promoting heliotherapy as a means of increasing resistance to the disease, but insisted on graduated exposure under strict supervision. He established a hospital school and a college for occupational training. Gauvain's happy and optimistic temperament infected staff and patients.

Koch's discovery of an invading bacillus revealed tuberculosis to be one malady whatever its manifestation, and we now know that joint disease is very frequently secondary to primary disease in the chest. It has long been customary to segregate pulmonary patients in sanatoria, and with the development of thoracic surgery to aim at rendering a patient non-infective on his return home. The establishment of country orthopaedic hospitals provided greater facilities for the treatment of patients with skeletal disease, hospitals like those at Margate and Sevenoaks having done pioneer work. Greater bed accommodation for the study of joint tuberculosis led to progressive knowledge of its treatment. In 1924 George Perkins wrote his prize monograph on The Diagnosis, Treatment and End Results of Tuberculous Disease of the Hip Joint. This work was based on an experience at the Country Orthopaedic Hospital at Pyrford. It was an able disquisition into the clinical nature of the disease and of its treatment, introducing a new abduction frame for prolonged conservative treatment. It was found that destructive disease of the femoral head very often ended in fibrous ankylosis of the joint, leading to an unreliable weight-bearing limb; a hip with osseous ankylosis at 35 degrees flexion was the best functional end-result for most purposes. This was difficult to obtain, because primary intra-articular operation was not in favour with English surgeons. This ideal was attained some years later by an extra-articular bone graft bridge from greater trochanter to ilium. And in $1932 \mathrm{H}$. C. Trumble of Melbourne achieved ischio-femoral arthrodesis by a tibial graft. H. A. Brittain followed with a solid fusion obtained by a TrumbleMcMurray procedure; a broad tibial graft was passed along the track of a displacement osteotomy of the femur to impinge in a prepared cavity in the ischium. The tendency to adduction in hip disease pressed the graft towards the pelvis; this arthrodesis is well adapted to bear the stress of weight bearing. Brittain fused other joints by so placing his bone grafts that they were subject to compression force during use of the limb. His early death was a loss to rational orthopaedic craftsmanship.

The commonest site for skeletal tuberculous disease is the spine; it is also the part that

VOL. 38 B, NO. 1, FEBrUARY 1956 
well illustrates the inherent power of recovery. In earlier days it was not uncommon to see individuals with a kyphosis whose spinal radiograph disclosed a healed destructive disease which could have been no other than tuberculosis and for which no treatment was received. On the other hand it is the place where the most distressing paralytic complication may occur, particularly in the mid-thoracic region, where the normal kyphosis is greatest and where the calibre of the spinal canal is smaller than elsewhere, thus allowing little accommodation for débris or exudate. Spinal tuberculosis with paraplegia was first accurately described by Percivall Pott in his monograph of 1779 . He differentiated between flaccid and spastic paralysis and noted that spasticity was the invariable rule of spinal cord pressure in vertebral caries. He concluded that the disease had its origin elsewhere in the body and was capable of revealing itself in a variety of organs-or, in modern terminology, tuberculosis is an infective disease with local manifestations. Continued recumbency in a plaster bed brings relief to most patients but there is a minority for whom operation is necessary. The earlier attempt to remove spinal cord pressure by laminectomy was discouraging because of its uncertain relief and its high mortality. As a substitute for laminectomy Ménard in 1894 introduced costotransversectomy. Transverse process and rib of diseased vertebra are removed, thus permitting a gloved finger to be cautiously insinuated between rhythmically moving pleura and vertebra until the abscess is reached; fluid pus and débris are evacuated without opening the spinal canal. For the following forty years Ménard's operation was favoured as the best radical procedure in the event of failure of paralytic recovery by recumbency. But further interest in paraplegia of Pott's disease was greatly stimulated by R. W. Butler and H. J. Seddon in their intensive studies of its etiology, pathology and treatment. About this period, in 1933, a patient with Pott's paraplegia was transferred by Mr Seddon to Mr Norman Capener at Plymouth with a suggestion that the spinal canal should be explored. Capener performed what he afterwards called lateral rhachotomy, removing not only rib and transverse process, as in Ménard's operation, but pedicle as well, thus providing an exposure of the canal; the cause of the spinal cord pressure was a spur projecting from the postero-inferior edge of a vertebral body, which was removed. Some years later G. L. Alexander and Norman Dott independently developed a similar operation. Antero-lateral decompression was a distinct advance and is the only safe procedure possible where the offending object is solid or semi-solid and contained within the spinal canal, whether it be massed granulation tissue, caseation, sequestrum, disc or bony spur.

Of surgeons whose work was intimately associated with country orthopaedic hospitals G. R. Girdlestone maintained an unremitting interest in the peculiar problems of the tuberculous cripple. He made many contributions to the subject, all of which he gathered up in his book of 1940 entitled Tuberculosis of Bone and Joint. It was more than a formal text-book in that the whole work was permeated with a personal experience at the Wingfield-Morris Orthopaedic Hospital for over twenty years. He advocated and described procedures for securing uninterrupted and adequate immobilisation but was disposed to venture upon radical operations earlier than most surgeons; osseous ankylosis by operation was for him both the curative and functional ideal. He was moved by the pathetic state of the paraplegic in spinal disease and proceeded to costo-transversectomy if recumbency tarried in its relief. His confidence in laminectomy was surprising, but that may well have been because antero-lateral decompression had hardly established itself; he welcomed it later.

Girdlestone in 1937 at Oxford had the distinction of appointment to the first chair of orthopaedic surgery in Britain, and his name is indissolubly linked with the Wingfield-Morris Orthopaedic Hospital which he founded. There he attracted men to watch his work and study the organisation of its regional clinics. He was a man of profound Christian belief and it was said there was something Franciscan in his affection for the poor and crippled. His friendship with Lord Nuffield was a potent influence in guiding that philanthropist's munificent medical benefactions. 
Girdlestone received a training at Baschurch, whereas other early disciples of Sir Robert Jones were trained at Liverpool, of whom McMurray and Aitken come readily to mind. McMurray came from Queen's University, Belfast, to Liverpool where he remained for the rest of his professional career. After a period at the Southern Hospital he became private assistant to Sir Robert, whom he served with filial devotion. He was appointed surgeon to the Northern Hospital, and later became Director of Orthopaedic Studies and eventually Professor. With the instituting by Liverpool University of a higher degree in orthopaedic surgery McMurray threw himself with great energy into the building of a postgraduate school. Graduates came to it from all over the Commonwealth for teaching and training in orthopaedic surgery, proceeding later to the degree of M.Ch.(Orth.). McMurray, a tall, handsome and commanding figure, was unfaltering in his fidelity to the tradition of Thomas and Robert Jones; he leavened his forceful and dogmatic teaching with native humour and a paternal care for his pupils. He contributed greatly to the surgery of the hip by his displacement osteotomy of the femur which he published in 1935. This operation was an adaptation of the bifurcation of Lorenz for unreduced congenital dislocation of the hip. McMurray declared that the operation could be performed in a few minutes and shock was negligible. He was careful in the placing of lower fragment: "Oblique osteotomy is now made in shaft of femur passing from below upwards and inwards at such a level that the inner end of lower fragment lies about $\frac{1}{2}$ inch below level of head of femur. Upper end of lower fragment is now displaced inwards and slightly upwards by means of a smooth lever and by abduction of leg so that shaft of femur comes to lie just below lower border of acetabulum." A plaster was retained for four to five months, during the last two of which the patient was allowed to get about weight bearing. When the plaster was discarded the patient in a few months regained comfortable movement at the hip. The operation was subsequently successfully adopted for non-union of a fracture of the neck of the femur.

McCrae Aitken migrated from Edinburgh to Liverpool and became one of the staunchest supporters of the Thomas tradition in orthopaedic surgery. In 1938 he wrote a valuable monograph entitled Hugh Owen Thomas: His Principles and Practice (Oxford University Press). On coming to London early in his career to pursue a higher qualification it caused him no little dismay to find that the caliper had no place in teaching hospitals in the treatment of a fracture or joint disease. He was about the first to be appointed to the military hospital at Shepherd's Bush, where his considerable experience was invaluable in demonstrating the use of the caliper and other Liverpool appliances in traumatic surgery and in teaching and training young officers from the United States and the Commonwealth. After the war he continued as surgeon to St Vincent's Orthopaedic Hospital and was appointed visiting surgeon at Oswestry, eventually succeeding Sir Robert Jones as surgical director. He devoted many years to the patient study of spinal deformity and wrote extensively about it. He was recognised by his colleagues as the best informed and the most successful amongst them in dealing with this difficult disability. He formulated a summary of his observations on the nature of spinal deformity and the principles which should guide treatment: "Scoliosis or rotato-lateral curvature of the spine, and kyphosis and lordosis or round and hollow back must all be taken in one group in any discussion of the deformities of the spinal column and trunk, for these several deformities blend and overlap to such an extent that they cannot be kept separate and distinct... Such deformity involves alterations in the relative positions of ribs and pelvis as well as of the spinal column, adaptive changes in muscles and ligaments and much the most important factor of all there are corresponding changes in that normal automatic reflex action of muscle taking part in maintaining the position of the body ... At least two distinctive groups of reflex controlled muscles take part, namely the static group and the respiratory group. In the static reflex group must be included all the muscles of the lower limbs, pelvis and trunk which are concerned in keeping the body erect and balanced ... In the respiratory reflex group are all the muscles concerned in maintaining respiration ...

VOL. 38 B, NO. 1, FEBRUARY 1956 
Disturbance of the proper reflex balance of the body is an essential factor which must always be kept in the forefront in considering the treatment of any case, whether an early mild case with little or no bony deformity or a later case with much distortion of the skeleton as well as alterations in the length and position of muscles. It is on this factor that the whole principle and practice of treatment by exercises or drill depends. Further, all correction of position by means of plaster (' forcible correction') or manipulations is really directed towards shifting the centre of gravity of the trunk as a whole and straightening out the trunk so that the centres of gravity of the several sections of the body may be near enough to one vertical line for a re-education of the co-ordination of the 'postural' muscles to maintain this posture automatically, without conscious effort." In practice these principles were worked out by him in great detail. He passed through several phases in his attempt at correction by plaster jacket, ultimately deciding upon the application of a plaster that combined the essential ideas of Hoke, Haglund and Abbot with additions of his own. Although he made no claim " to have made a crooked vertebral column as straight as if it had never been distorted" he certainly did permanently improve the posture and well-being of very many individuals crippled with severe spinal deformity.

Among the countless casualties of the first world war were great numbers of peripheral nerve injuries, thus providing an unprecedented opportunity for the study of nerve regeneration. In this investigation there was happy cooperation between neurology and orthopaedics which was reflected in the Committee on Peripheral Nerve Injuries appointed by the Medical Research Council. Walter Rowley Bristow, who had displayed an intense interest in nerve and muscle injuries, was elected to this committee. During the war he cooperated with Sir Harry Platt in the study of nerve regeneration. The fruit of their investigation they communicated to the International Society of Surgery in 1923, in a valuable report on the remote results of operation for peripheral nerve injuries. They concluded that if the nerve ends could not be joined an autogenous cable graft should be used to bridge the gap. End to end suture in most patients produced an imperfect functional recovery; out of a large number of consecutive operations 20 per cent were complete failures. The extent of regained function after suturing varied with the particular nerve severed; the radial was head of the list; at least 50 per cent of patients with paralysis of this nerve had complete recovery after operation. Ulnar and median paralysis were disappointing. In the case of the ulnar nerve complete restoration of power in the intrinsic muscles of the hand was almost unknown; if recovery occurred it was invariably in the hypothenar muscles alone. But in spite of such indifferent ulnar nerve regeneration the hand often retained much of its usefulness except when finer coordinated movements of the fingers were required. With regard to the median nerve paralysis sensory recovery was always inadequate, causing considerable depreciation in manual function. Results of sciatic nerve suture were poor; a considerable number of paralysed lower limbs were ultimately amputated.

Rowley Bristow was appointed orthopaedic surgeon to St Thomas's Hospital in 1919. In a few years he organised and built up such a department that the number of patients requiring admission strained his allotted beds. Forced to look afield he made contact with an Anglican home for crippled children at Pyrford in Surrey; gradually this institution was transformed into a country orthopaedic hospital somewhat reminiscent of the evolution of Baschurch. There was something unique about this arrangement in that the Pyrford Hospital was not so much a country branch of St Thomas's as an extension of its orthopaedic department. Bristow's particular interest was directed towards traumatic orthopaedic surgery; he wrote on nerve and muscle injuries, internal derangement of the knee joint and fractures. He was a stimulating teacher of undergraduates, who crowded his clinic; he picked out essentials with clarity and emphasis, at the same time handling his patients with friendly understanding and good humour. Bristow was endowed with abounding vitality; a tireless worker with a zest for life and its friendships. As a tribute to his work at Pyrford the hospital has been named after him. 
The growth of bone is of particular interest in skeletal surgery. It stimulated John Hunter to pursue experimental work on pigs which led him to declare that long bones were lengthened from the ends near the epiphysis and became thicker by deposition of new bone under the periosteum. Again bone was constantly undergoing change with simultaneous absorption and deposition of osseous tissue. Macewen first succeeded in grafting human bone from one individual to another and thereafter devoted many years to experimental investigation of bone growth, from which he concluded that the growth of a long bone occurred at the diaphysis, for he believed that the cartilaginous growth disc belonged to the diaphysis and not to the epiphysis. He also believed that periosteum had no osteogenetic power-it was purely a limiting membrane giving direction to bone growth but taking no active part in it.

In 1933 Professor H. A. Harris published a book of much originality entitled Bone Growth in Health and Disease (Oxford University Press), the result of experimental researches at the Institute of Anatomy at University College and University College Hospital. He noted transverse lines which cross the shafts of long bones, which he traced to arrested growth occurring during illness or disturbance of nutrition in childhood or early youth. Harris paid considerable attention to bone growth in deficiency diseases, with descriptions of histological and radiographic changes observed in proliferating cartilage, calcifying cartilage and bone; and he stressed how each process differed in its mutation. The osteoblast was a cartilage cell endowed with bone-forming properties. Growth at the end of a long bone was restricted to a mitotic annulus of dividing cartilage cells. Calcification he believed to be a biochemical process. He discovered that cartilage cells approaching the line of ossification contained glycogen which disappeared on conversion to bone. He suggested that glycogen was hydrolysed to hexose phosphoric esters which under the action of phosphatase and circulating calcium combined to form a deposit of insoluble calcium phosphate in the matrix.

\section{RECENT TRENDS}

The history of orthopaedic surgery is one of progressive evolution; for the first forty years it was concerned with the correction of congenital and paralytic deformities by splinting, manipulation and tenotomy. From about 1880 onwards the adoption of antisepsis permitted a bolder attack beginning first with osteotomy and advancing later to correction by open exposure. The war of 1914 and after quickened the pace. An answer for the insecurity of crippling was sought by joint stability through operation whether by tendon transplantation or arthrodesis or both. The open air conservative treatment of skeletal tuberculosis, with bone-graft surgery as a refinement, became the peculiar province of orthopaedic surgery and an increasing interest developed in the orthopaedics of trauma as a direct legacy of the war itself.

The story of the finding of penicillin and its development is already a romantic classic of science. The drifting of a mould spore on to Alexander Fleming's plate was as providential as the timely placing of him there with a mind already prepared to see its significance. "I found that while the crude culture fluid in which the mould had grown was strongly antibacterial it was non-toxic to animals and human leucocytes." It was fortunate too that Howard Florey was at that very time turning his attention to bacterial inhibition; "My own interest in the phenomenon of bacterial inhibition began in the 1920s." He, with Professor E. B. Chain and the rest of the Oxford team, succeeded in extracting a pure stable form of penicillin for human injection. Since that time the soil of the earth has been combed in many countries for other naturally occurring antibacterial substances. In $1944 \mathrm{Dr}$ Selman Waksman of New Jersey isolated streptomycin from streptomyces griseus, a body antagonistic to the tubercle bacillus. These and other natural antibiotics together with synthetic sulphonamides introduced by Professor Domagk of Elberfeld in 1935 have revolutionised therapeutic practice.

The new therapy has had a very beneficial influence on orthopaedic surgery. The lurking

VOl. 38 B, No. 1, febrUARY 1956 
threat of sepsis has been greatly mitigated, protection has been given to operative procedures beyond what was possible by surface antiseptics alone. Bone infection such as osteomyelitis is much more readily controlled and the compound fracture is less menacing to life and limb. Chemotherapy in joint tuberculosis retards the destructive process of the disease, shortens the duration of the malady and permits of an earlier fusion operation. When invasion of a joint is comparatively early, with no sign of bone erosion, rigid immobilisation may be relaxed and joint movement permitted under supervision.

There is change in the incidence of disease. Rickets has all but vanished; on its deformities osteotomy at one time flourished. Wonderful to relate, tuberculosis at long last is a declining disease due to protective and improved curative therapy and social betterment with its clean milk, better feeding and education. Infantile paralysis is still a dread menace, but there is good reason for believing that a safe protective vaccine will soon emerge.

\section{REFERENCES}

Adams, W. (1860): On the Reparative Process in Human Tendons. London: J. Churchill.

Adams, W. (1882): Lectures on the Pathology and Treatment of Lateral and Other Forms of Curvature of the Spine. Second edition. London: J. \& A. Churchill.

AItken, D. M. (1935): Hugh Owen Thomas: His Principles and Practice. London: Humphrey Milford Oxford University Press.

Albee, F. H. (1911): Transplantation of a Portion of the Tibia into the Spine for Pott's Disease. Journal of the American Medical Association, 57, 885.

Albee, F. H. (1919): Orthopedic and Reconstruction Surgery. Philadelphia and London: W. B. Saunders Company.

ANDRY, N. (1743): Orthopaedia. London: A. Millar.

Clarke, J. J. (1910): Congenital Dislocation of the Hip. London: Baillière, Tindall and Cox.

Davy, Sir Humphry (1800): Researches, Chemical and Philosophical, Chiefly Concerning Nitrous Oxide. London: J. Johnson.

ElmsLIE, R. C. (1913): Coxa Vara: its Pathology and Treatment. London: Henry Frowde Oxford University Press.

Elmslie, R. C. (1914): Fibrocystic Disease of the Bones. British Journal of Surgery, 2, 17.

Fairbank, Sir T. (1951): An Atlas of General Affections of the Skeleton. Edinburgh and London: E. \& S. Livingstone Ltd.

Fleming, A. (1943): Discussion on Penicillin. Proceedings of the Royal Society of Medicine (Section of Experimental Medicine and Therapeutics), 37, 101.

GiRDLestone, G. R. (1940): Tuberculosis of Bone and Joint. London: Humphrey Milford Oxford University Press.

Godlee, Sir R. J. (1917): Lord Lister. London: Macmillan \& Co. Ltd.

Groves, E. W. Hey (1921): On Modern Methods of Treating Fractures Including the Jacksonian Prize Essay on Bone Grafting. Second edition. Bristol: John Wright \& Sons Ltd.

Harris, H. A. (1933): Bone Growth in Health and Disease. London: Humphrey Milford Oxford University Press.

James, J. H. (1840): The Retrospective Address in Surgery from July 1836 to July 1839 . Transactions of the Provincial Medical and Surgical Association, 8, 214.

Jones, A. Rocyn (1937): The Evolution of Orthopaedic Surgery in Great Britain. Proceedings of the Royal Society of Medicine (Section of Orthopaedics), 31, 19.

JONES, R. (1908): An Operation for Paralytic Calcaneo-Cavus. American Journal of Orthopedic Surgery, 5, 371. Jones, R. (1915): Injuries of Joints. London: Henry Frowde Oxford University Press, Hodder and Stoughton. JONES, R. (1917): Notes on Military Orthopaedics. London: Cassell \& Company Ltd.

LambrinUdi, C. (1927): New Operation on Drop-Foot. British Journal of Surgery, 15, 193.

Lirtle, E. Muirhead (1922): Artificial Limbs and Amputation Stumps. London: H. K. Lewis and Co. Ltd. Lirtle, E. Muirhead (1932): History of the British Medical Association 1832-1932. London: British Medical Association.

LittLe, W. J. (1839): A Treatise on the Nature of Club-Foot and Analogous Distortions. London: W. Jeffs. Lirtle, W. J. (1862): On the Influence of Abnormal Parturition, Difficult Labours, Premature Birth, and Asphyxia Neonatorum, on the Mental and Physical Condition of the Child, especially in Relation to Deformities. Transactions of the Obstetrical Society of London, 3, 293.

MACEWEN, W. (1878): On Antiseptic Osteotomy. Lancet, ii, 911. 
MaCewen, W. (1912): The Growth of Bone. Glasgow: James Maclehose and Sons.

MCMurRay, T. P. (1935): Osteo-arthritis of the Hip-Joint. British Journal of Surgery, 22, 716.

Nicol ADONI, C. (1882): Nachtrag zum Pes calcaneus und zur Transplantation der Peronealsehnen. Archiv für Klinische Chirurgie, 27, 660.

Openshaw, T. H. (1898): On Tendon Implantation. Transactions of the British Orthopaedic Society, 3, 78. PAGeT, S. (1914): Pasteur and After Pasteur. London: Adam and Charles Black.

Perkins, G. (1926): The Diagnosis, Treatment and End Results of Tuberculous Disease of the Hip Joint. London: Humphrey Milford Oxford University Press.

Potr, P. (1790): The Chirurgical Works of Percivall Pott, F.R.S., to Which are Added a Short Account of the Life of the Author, by James Earle, Esq. Third edition. Three volumes. London: printed for J. Johnson, G. G. J. and J. Robinson, T. Cadell, J. Murray, W. Fox, J. Bew, S. Hayes, and W. Lowndes.

RöNTGEN, W. C. (1896): On a New Kind of Rays. Nature, 53, 274; 377.

Thомas, H. O. (1875): Diseases of the Hip, Knee and Ankle Joints. Liverpool: T. Dobb \& Co.

TubBy, A. H. (1896): Deformities. A Treatise on Orthopaedic Surgery. London: Macmillan \& Co. Ltd.

TubBy, A. H. (1912): Deformities Including Diseases of the Bones and Joints. Second edition. Two volumes. London: Macmillan \& Co. Ltd.

TubBy, A. H. (1920): A Consulting Surgeon in the Near East. London: Christophers.

TuBby, A. H., and Jones, R. (1903): Modern Methods in the Surgery of Paralyses. London: Macmillan \& Co. Ltd.

Watson-Jones, R. (1940): Fractures and other Bone and Joint Injuries. Edinburgh: E. \& S. Livingstone Ltd. 